Lutsiv I. I., Hudyma A. A., Pereviznyk B. O., Marushchak M. I. Dynamics of proximal and distal transport of sodium in case of bilateral gonadectomy and the efficacy of hormonal replacement therapy. Journal of Education, Health and Sport. 2021;11(1):338345. eISSN 2391-8306. DOI http://dx.doi.org/10.12775/JEHS.2021.11.1.033

https://apcz.umk.pl/czasopisma/index.php/JEHS/article/view/JEHS.2021.11.1.033

https://zenodo.org/record/5123020

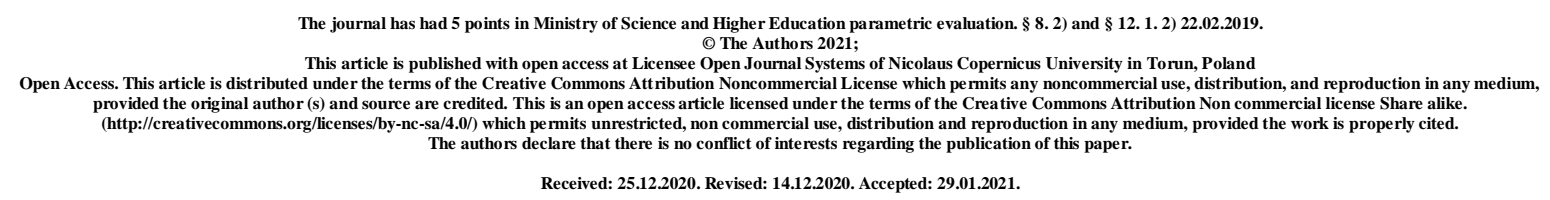

UDK 616.61:618.11-089.87]-085.357

\title{
DYNAMICS OF PROXIMAL AND DISTAL TRANSPORT OF SODIUM IN CASE OF BILATERAL GONADECTOMY AND THE EFFICACY OF HORMONAL REPLACEMENT THERAPY
}

\section{I. Lutsiv, A. A. Hudyma, B. O. Pereviznyk, M. I. Marushchak}

\section{Ternopil National Medical University}

\begin{abstract}
Introduction. The characteristic feature of current trauma in Ukraine and in the world is the prevalence of highly energetic skeletal trauma which is followed by the appearance of combined and multiple injuries with the formation of multiorgan dysfunction and failure. Because of the increase of life duration, the high interest of current traumatology is the investigation process of trauma course in older people. Among them the high interest is given to females in postmenopausal period. The decrease of estrogen level causes very unfavorable ground for the trauma course. However, the influence of severe trauma on changes in proximal and distal transport of sodium in case of hypoestrogenic state is not fully investigated. There is no available data concerning the effectiveness of hormonal replacement therapy in this condition.

The goal of the study: is to investigate the influence of cranioskeletal injury on the dynamics of proximal and distal sodium transport in rats with bilateral ovariectomy in the period of late changes of traumatic disease and evaluate the effectiveness of hormonal replacement therapy.
\end{abstract}


Materials and methods. Experiments were performed on 42 non-linear white female rats with the weight of 200-220 g. The model of hypoestrogenic state was performed via surgical removal of the ovaries. 1 month after the gonadectomy in rats skeletal trauma was performed. As a treatment option in one subgroup of rats with gonadectomy and cranioskeletal injury we performed hormonal replacement therapy. The control groups were formed by intact rats and osteoporotic rats 1 month after gonadectomy which were not injured. In control groups and after 1 and 2 months of posttraumatic period we were investigating the functional state of kidneys by performing the water upload method. Afterwards we performed the laboratory checkup of creatinine and sodium levels in serum and urine and additionally calculated the values of proximal and distal sodium transport.

Results and its discussion. It was found that the level of proximal and distal sodium transport depends on the estrogen level, the decrease of its secretion leads to the decrease of sodium reabsorption in tubules and the increase in secretion. These changes were more prevalent in proximal tubules. In the course of trauma 1 month after posttraumatic period the value was decreasing in both research groups. However, in rats with gonadectomy the changes were much bigger and stayed at the same level until the $2^{\text {nd }}$ month of the experiment. In rats without gonadectomy these values were achieving the same levels as control group until $2^{\text {nd }}$ month. The use of combined hormonal replacement therapy caused the increase of proximal and distal sodium transport in comparison to the group without receiving treatment. The results that we got though was not achieving the level of rats without gonadectomy, but it showed the perspective for the use of combined hormonal replacement therapy in case of hypoestrogenic state for the decrease of renal dysfunction.

Conclusions: Bilateral ovariectomy in female rats after 1 month shows the decrease of proximal and distal sodium levels comparing to rats with preserved gonads. The cranioskeletal injury that happened 1 month after bilateral ovariectomy causes the much bigger decrease of proximal and distal sodium transport comparing to rats with preserved gonads. The use of combined hormonal replacement therapy caused lower changes in proximal and distal sodium transport comparing to rats without this treatment.

Key words: gonadectomy; cranioskeletal trauma; diuresis; proximal and distal sodium transport.

Introduction. The characteristic feature of current trauma in Ukraine and in the world is the prevalence of highly energetic skeletal trauma which is followed by the appearance of combined and multiple injuries [1]. The biggest danger of this trauma is the development of 
systemic dysfunction. Systemic changes lead to the organs' dysfunction that are remote from the location of primary injury with the development of multiple organ insufficiency and failure which leads to death,

Because of the increase of life duration, the high interest of current traumatology is the investigation process of trauma course in older people. Among them the high interest is given to females in postmenopausal period. The decrease of estrogen levels lead to the increased formation of active forms of oxygen in internal organs, activation of lipid peroxidation, decrease of antioxidant protection [2]. All of the above causes the unfavorable ground for the trauma course where the prooxidant mechanisms are the starting points for the development of multiorgan failure [3, 4].

One of the sensitive organs that react for the estrogen deficiency and pathogenic mechanisms of severe skeletal injury are the kidneys. It is caused by increased blood supply in physiologic conditions, very huge energy consumption of tubular epithelium for active reabsorption of the primary urine and provision of water and electrolyte homeostasis [5]. However, the influence of severe trauma on interruption of proximal and distal sodium transport in case of hypoestrogenic state is not fully investigated. There is no data available about the effectiveness of hormonal replacement therapy as well.

Goal of the study: is to investigate the influence of cranioskeletal trauma on the dynamics of proximal and distal sodium transport in rats with bilateral ovariectomy in the period of late consequences of traumatic disease and evaluate the effectiveness of hormonal replacement therapy.

Materials and methods. Experiments were performed on 42 non-linear white female rats with the weight of 200-220 g. The model of hypoestrogenic state was performed via surgical removal of the ovaries [6]. The model of cranioskeletal trauma was performed 1 month after surgical gonadectomy by the application of dosed cranial kick with the further development of moderate degree closed traumatic brain injury and additional dosed femoral kick by using the wedge-shaped nozzle device to achieve closed femoral fracture [7]. In comparison group these traumas were also modeled in healthy rats. As treatment approach in one of subgroups with gonadectomy and cranioskeletal injury we performed hormonal replacement therapy which included the intraabdominal administration of hexestrol ("Synestrol", Biopharma, Ukraine) dosed $0,1 \mathrm{mg} \cdot \mathrm{kg}^{-1}$ and progesterone ("Progesterone", Pharmak, Ukraine) dosed $5 \mathrm{mg}$ per 1 rat [8]. Drugs were prepared and diluted in oil and were administered everyday during the whole period after cranioskeletal injury.

Control groups were composed of intact rats and rats with osteoporosis 1 month after 
gonadectomy which were not traumatized.

In control groups and 1 and 2 months after posttraumatic period in rats we performed the analysis of functional state of kidneys by water upload method [9]. Via metal gastric tube we administered the water of $30{ }^{\circ} \mathrm{C}$ in the volume $5 \%$ of body weight. The urine was collected during 2 hours and the diuresis was counted. After urine collection rats were removed from the experiment while being in state of thiopental sodium anesthesia with performance of complete heart bleeding. We checked levels of creatinine and sodium in serum and urine by unified method of biochemical analyzer "Humalyzer 2000". We also counted the levels of proximal and distal sodium transport [9].

During the work with laboratory animals we followed the international regulations on humane work with rats according to "European Convention for the Protection of Vertebrate Animals used for Experiemental and Other Scientific Purposes" 1986. All surgical approaches and trauma modeling were performed during thiopental sodium anesthesia $\left(40 \mathrm{mg} \cdot \mathrm{kg}^{-1}\right)$. Euthanasia of rats was done by performance of complete heart bleeding.

Statistical analysis of obtained data was performed by the use of Mann-Whitney criteria in STATISTICA 10.0 («StatSoft, Inc.», USA).

Results and its discussion. As it is indicated in Table 1, the value of proximal sodium transport in control group with gonadectomy was statistically and significantly lower comparing to rats without gonadectomy (for $29,3 \%, \mathrm{p}<0,05$ ). Distal sodium transport of in animals with gonadectomy had the tendency for smaller value; however the result was not statistically significant.

The model of cranioskeletal trauma in the group of rats without gonadectomy 1 month after posttraumatic period comparing to control group was showing the decrease of proximal sodium transport (for $22 \%$ ) however the result was not statistically significant ( $>00,05$ ). After 2 months the value increased but it was not significantly changed comparing to control $(\mathrm{p}>0,05)$.

The application of cranioskeletal trauma in rats with gonadectomy comparing to control and 1 month after posttraumatic period lead to statistically significant decrease of proximal sodium transport (for $38,8 \%, p<0,05$ ). On the same level the value was kept even 2 months after the trauma $(\mathrm{p}>0,05)$.

The comparison of research groups concerning the value of proximal transports showed that in rats group with gonadectomy 1 and 2 months after the value was statistically and significantly lower comparing with animals without gonadectomy (respectively for 44,5 and $62,4 \%, \mathrm{p}<0,05)$. 
Table 1 - Dynamics of proximal and distal sodium transport in rats with cranioskeletal injury and bilateral ovariectomy (Me (LQ; UQ)) - median (lower and upper quartiles)

\begin{tabular}{|c|c|c|c|c|}
\hline \multirow{2}{*}{$\begin{array}{l}\text { Condition in } \\
\text { experiment }\end{array}$} & \multirow{2}{*}{ Control group } & \multicolumn{2}{|c|}{ Duration of monitoring } & \multirow[b]{2}{*}{$\mathrm{p}$} \\
\hline & & 1 month & 2 month & \\
\hline \multicolumn{5}{|c|}{ Proximal transport, $\mathrm{mcmol} \cdot \mathrm{min}^{-1} \cdot 100 \mathrm{~g}^{-1}$} \\
\hline Preserved gonads & $\begin{array}{c}49,96 \\
46,69 ; 55,49 \\
(n=6)\end{array}$ & $\begin{array}{c}38,95 \\
36,73 ; 45,61 \\
(n=6)\end{array}$ & $\begin{array}{c}52,27 \\
45,30 ; 55,35 \\
(n=6)\end{array}$ & $>0,05$ \\
\hline Gonadectomy & $\begin{array}{c}35,32^{\#} \\
33,10 ; 36,90 \\
(n=6)\end{array}$ & $\begin{array}{c}21,61^{* \#} \\
19,67 ; 23,38 \\
(n=6)\end{array}$ & $\begin{array}{c}19,66^{* \#} \\
18,94 ; 21,03 \\
(n=6)\end{array}$ & $>0,05$ \\
\hline \multicolumn{5}{|c|}{ Distal transport, $\mathrm{mcmol} \cdot \mathrm{min}^{-1} \cdot 100 \mathrm{~g}^{-1}$} \\
\hline Preserved gonads & $\begin{array}{c}4,59 \\
4,59 ; 4,63 \\
(n=6)\end{array}$ & $\begin{array}{c}3,70^{*} \\
3,58 ; 4,24 \\
(n=6)\end{array}$ & $\begin{array}{c}4,35 \\
4,18 ; 4,44 \\
(n=6)\end{array}$ & $<0,05$ \\
\hline Gonadectomy & $\begin{array}{c}4,37^{\#} \\
4,30 ; 4,47 \\
(n=6)\end{array}$ & $\begin{array}{c}2,69^{* \#} \\
2,49 ; 2,87 \\
(n=6)\end{array}$ & $\begin{array}{c}2,50^{* \#} \\
2,46 ; 2,64 \\
(n=6)\end{array}$ & $>0,05$ \\
\hline
\end{tabular}

Notes:

$1 .^{*}$ - changes in values comparing to control group statistically significant $(p<0,05)$;

2. \# - changes of value among the groups of rats with preserved gonads and with gonadectomy statistically significant $(p<0,05)$;

3. $p$ - possibility of differences of value in between $1^{\text {st }}$ and $2^{\text {nd }}$ month of experiment.

In the same time the value of distal sodium transport in rats without gonadectomy 1 month after cranioskeletal trauma comparing to control group was statistically and significantly decreasing (for $21,8 \%, p<0,05$ ). 2 months after posttraumatic period the value was increasing comparing to previous time of monitoring (for $21,2 \%, \mathrm{p}<0,05$ ) and reached the level of control group ( $p>0,05)$.

In rats with gonadectomy the modeling of cranioskeletal trauma compared to control 1 month after posttraumatic period also lead to the decrease of the value of proximal sodium transport (for $38,4 \%, p<0,05$ ), but until $2^{\text {nd }}$ month it stayed at the same level $(p>0,05)$.

The comparison of research groups based on the value of distal sodium transport showed that in rats group with gonadectomy during all the time of posttraumatic period the value was statistically and significantly lower than in rats group without gonadectomy (respectively for 25,1 and $42,5 \%(p<0,05)$.

The use of combined hormonal replacement therapy in rats with gonadectomy (Table 2) 2 month after the experiment was followed by significant increase of proximal transport compared to animals without treatment - for $78,4 \%\left(\mathrm{p}_{2}<0,05\right)$. 
Table 2 - Influence of combined hormonal replacement therapy on the level of proximal and distal transport 2 months after combined cranioskeletal trauma together with bilateral ovariectomy (Me (LQ; UQ)) - median (lower and upper quartile)

\begin{tabular}{|c|c|c|c|c|}
\hline \multirow{3}{*}{ Value } & \multirow{3}{*}{$\begin{array}{l}\text { Control group } \\
\text { (preserved } \\
\text { gonads) } \\
(n=6)\end{array}$} & \multicolumn{3}{|c|}{2 months after trauma } \\
\hline & & \multicolumn{2}{|c|}{ Without treatment } & \multirow{2}{*}{$\begin{array}{c}\text { Gonadectomy + } \\
\text { replacement } \\
\text { therapy }(n=6)\end{array}$} \\
\hline & & $\begin{array}{c}\text { Preserved } \\
\text { gonads } \\
(n=6)\end{array}$ & $\begin{array}{l}\text { Gonadectomy } \\
(n=6)\end{array}$ & \\
\hline $\begin{array}{l}\text { Proximal transport, } \\
\mathrm{mcmol} \cdot \mathrm{min}^{-1} \cdot 100 \mathrm{~g}^{-1}\end{array}$ & $\begin{array}{c}49,96 \\
46,69 ; 55,49 \\
(n=6)\end{array}$ & $\begin{array}{c}52,27 \\
45,30 ; 55,35\end{array}$ & $\begin{array}{c}19,66^{*} \\
18,94 ; 21,03 \\
\mathrm{p}_{1}<0,05 \\
(\mathrm{n}=6)\end{array}$ & $\begin{array}{c}35,08^{*} \\
33,70 ; 37,52 \\
\mathrm{p}_{1}<0,05 \\
\mathrm{p}_{2}<0,05 \\
(\mathrm{n}=6)\end{array}$ \\
\hline $\begin{array}{l}\text { Distal transport, } \\
\mathrm{mcmol} \cdot \mathrm{min}^{-1} \cdot 100 \mathrm{~g}^{-1}\end{array}$ & $\begin{array}{c}4,59 \\
4,59 ; 4,63 \\
(n=6)\end{array}$ & $\begin{array}{c}4,35^{*} \\
4,18 ; 4,44 \\
\\
(n=6)\end{array}$ & $\begin{array}{c}2,50^{*} \\
2,46 ; 2,64 \\
\mathrm{p}_{1}<0,05 \\
(\mathrm{n}=6)\end{array}$ & $\begin{array}{c}3,89^{*} \\
3,31 ; 3,41 \\
\mathrm{p}_{1}<0,05 \\
\mathrm{p}_{2}<0,05 \\
(\mathrm{n}=6)\end{array}$ \\
\hline
\end{tabular}

Notes:

1. ${ }^{*}$ - changes in values comparing to control group statistically significant $(p<0,05)$;

2. $\mathrm{p}_{1}$ - probability of differences of the value about the group without treatment with preserved gonads 2 months after posttraumatic period;

3. $\mathrm{p}_{2}$ - probability of differences of the value about the group without treatment with gonadectomy 2 months after posttraumatic period.

However if to compare with animals that had preserved gonads the value was significantly lower (for $32,9 \%, \mathrm{p}_{1}<0,05$ ) and compared to control group - for $29,8 \%$ $(p<0,05)$. In the same time the value of distal sodium transport after combined hormonal replacement therapy increased in 55,6\% $\left(\mathrm{p}_{2}<0,05\right)$, but was lower comparing to the animal group that had preserved gonads (for $10,6 \%, \mathrm{p}_{1}<0,05$ ) and comparing to control (for $15,2 \%$, $\mathrm{p}<0,05)$.

Received results show that the value of proximal and distal sodium transport depends on the estrogen levels, the decrease of its synthesis is followed by the decrease of sodium reabsorption in tubules and the increase of its secretion. The same results after ovariectomy was received by other authors [10]. These changes were more significant in proximal tubules where sodium reabsorption is more energy-dependent [9].

Under the influence of trauma 1 month after posttraumatic period the value in both groups was decreased, which is one of the manifestations of the pathogenic factors influence of traumatic disease [11]. However, these changes were more significant in rats with gonadectomy and stayed at the same level until the $2^{\text {nd }}$ month of the experiment. At the same 
time in rats with preserved gonads the investigated values reached the level of the control group up to $2^{\text {nd }}$ month of posttraumatic period.

If to summarize, estrogens play an important role in provision of the proper tubular activity of kidneys in case of trauma. Its deficiency causes the slowdown of sodium reabsorption and potentially, the increase of its secretion. The sodium loss in the same time, promotes the water and electrolyte imbalance and leads to the more severe systemic dysfunction [12].

This assumption has found its confirmation after the use of combined hormonal replacement therapy. If to compare with animals without treatment, we found the increase of proximal and distal sodium transport. Though the received data didn't achieve the level of rats with preserved gonads, but proved the potentially good effects of combined hormonal replacement therapy in case of hypoestrogenic state for the decrease of renal dysfunction.

Conclusions: 1. Bilateral ovariectomy in female rats after 1 month is followed by the decrease of proximal sodium transport compared to rats with preserved gonads.

2. The application of cranioskeletal trauma 1 month after bilateral ovariectomy causes significantly bigger decrease of proximal and distal sodium transport 1 month after trauma comparing to rats with trauma without removed gonads which don't decrease after posttraumatic period.

3. The use of hexestrol with treatment goals in dose $0,1 \mathrm{mg} \cdot \mathrm{kg}^{-1}$ and progesterone in dose $5 \mathrm{mg}$ to rats with gonadectomy during posttraumatic period after cranioskeletal injury causes less significant changes in proximal and distal sodium transport comparing to rats without treatment.

Perspectives of further research. In perspective it is needed to receive more profound data about renal dysfunction in case of gonadectomy and cranioskeletal trauma with additional evaluation of the effectiveness of combined hormonal replacement therapy.

\section{References}

1. Huryev S. O., Fil A. Yu., Tanasiyenko O.M. Analysis of direct reasons of death in victims with polytrauma and skeletal damage. Trauma. 2015. V.16, No.4. P. 7-10.

2. Hudyma A. A. Kashchak T. V., Shepitko K.V. Antioxidant, prooxidant and cytokine balance in late period of combined trauma in experiment. World of Medicine and Biology. 2019. No. 1. P. 42-47.

3. Influence of two-hour tourniquets ischemia of limb and acute blood loss on systemic disorders of the body in the reperfusion period (experimental study) / I. I. Horban, 
A. A. Hudyma, R. V. Maksymiv, I. V. Antonyshyn. Wiadomości Lekarskie. 2020. Vol. LXXIII, Is. 7. P. 1330—1333. DOI: 10.36740/WLek202007104.

4. Shatsyi V.V. Pecularities of proximal and distal sodium transport in case of acute bleeding, complicated by ischemia and reperfusion of the limb and its treatment in experiment. Medical and Clinical Chemistry. 2019. V. 21, No. 4. P. 127-133.

5. Kamyshnikov V.S., Kovalenko Yu.D., Kokhnovych N.N. Clinical and laboratory monitoring of biochemical markers of osteoporosis in experiment. Achievements of medical science of Belarus. 2003. [Mode of access] http://med.by/dmn/book.php?book=03-18_10.

6. Borys R.M., Hozhenko A.I., Hudyma A.A. Dynamics of lipid peroxidation in period of early and late manifestations of traumatic disease in case of experimental cranioskeletal trauma and its treatment with cellular therapy. Clinical and experimental pathology. 2013. Vol. 12, No. 2 (44). P. 31-34.

7. Mashevskyi A.S., Lukovych A.I., Datsko V.A. Structural changes of liver, brain and boned of rats in cranioskeletal injury in case of experimental hypoestrogenic osteoporosis 2 months after posttraumatic period and its treatment with hormonal replacement therapy. Applied aspects of morphology: collection of materials of the scientific and practical conference, October 20-21 2016. Ternopil 2016. P.107-109.

8. Rohovyi Yu.Ye. Pathophysiology of hepatorenal syndrome in poyuric stage of sulemic nephropathy. Chernivsti: «Misto», 2012. 200 p.

9. Roles of estrogen and progesterone in modulating renal nerve function in the rat kidney / J. B. Graceli, M. A. Cicilini, N. S. Bissoli [et al.]. Brazilian Journal of Medical and Biological Research. 2013. Vol. 46. P. 521-527, http://dx.doi.org/10.1590/1414$\underline{431 X 20132666}$

10. Kovalyov V.V., Popovych D.V. Dynamics of functional state of kidneys in early period after cranioskeletal injury of different severity, complicated by hemorrhage. Bulletin of scientific research. 2018. No.4. P. 184-189.

11. Functional renal reserve: physiological value of functional renal reserve and the reasoning of the methodology of its calculation / A.I. Hozhenko, A.V. Kravchuk, V.M. Sirman, O. P. Nykytenko, L.V. Romaniv // Kidneys. - 2015. - No.4. - P. 7-11. Mode of access: http://nbuv.gov.ua/UJRN/nirku_2015_4_4 